\title{
Optimization Using Solvent-Free Microwave Hydro-diffusion Gravity Extraction of Onion Oil from Allium cepa by Response Surface Methodology
}

\author{
Yeni Variyana $^{1}$ and Mahfud Mahfud ${ }^{1 *}$
}

\begin{abstract}
Extraction from Allium cepa using solvent-free microwave extraction (SFME) was chosen as a method in the extraction process. The method is combined with microwave hydro-diffusion gravity (MHG) technique. In this paper, onion oil was extracted from Allium cepa using solvent-free microwave and hydro-diffusion gravity extraction which is as an alternative technique to produce onion oil and it has several advantages in terms of product quality and quantity. Furthermore, response surface methodology (RSM) was designed to evaluate the single factor and interaction effects of mass of raw material $(\mathrm{g})$, microwave power $(\mathrm{W})$ and extraction time (min) for optimization from experimental data. The highest yield was obtained from this research at $100 \mathrm{~g}, 450 \mathrm{~W}$ and $15 \mathrm{~min}$ is $2.5875 \%$. Response surface methodology gave the optimum condition at $99.738 \mathrm{~g}, 465.067 \mathrm{~W}$, and $17.817 \mathrm{~min}$ is $2.677 \%$. The error rates between the experimental and predicted model which are less than $5 \%$ indicate that values obtained in optimal conditions correspond to theoretical values and it can be used as a reference for optimizing.
\end{abstract}

Keywords-Allium cepa, SFME, MHG, Onion Oil, Yield, RSM, Optimal Conditions.

\section{INTRODUCTION}

$\mathrm{O}$ ne of the strategic commodities in Indonesia is onion (Allium cepa). It is widely cultivated in Southeast Asia [1] and can live in a subtropical climate [2]. Onion is one type of vegetable that is used as an ingredient and seasoning in the food industries. Not only for spices, onions also have many benefits for health. In every $100 \mathrm{~g}$ of it, the protein content is about $15 \%, 0.3 \%$ fat, $9.2 \%$ carbohydrate, $50 \mathrm{IU}$ carotene, $30 \mathrm{mg}$ thiamin, niacin 20 $\mathrm{mg}$, riboflavin $0.04 \mathrm{mg}, 9 \mathrm{mg}$ carbonic acid, potassium $334 \mathrm{mg}$, iron $0.8 \mathrm{mg}$, and phosphorus $40 \mathrm{mg}$. Onions have chemical and biological properties, such as antimutagenic [3], [4], an antimicrobial agents [5]-[7], antioxidant activities [6]-[8], antidiabetic [9], [10], and antitumor activities [6]. Then, the extraction process from the onion can produce essential and onion oils, which give benefits for human life. The onion oil of the extract would be good value of the product and a potential source for extraction processes in the industry. Recent studies have been done to extract the essential (onion) oil from onion. It has organosulfur compounds and the main compounds are dominated [11].

The previous research has been confirmed by conventional method such as maceration, steamdistillation, soxhlet extraction, etc. There have been many extraction methods developed to extract the onions, including pressurized liquid extraction [12], the ultrasound method [13], supercritical fluid extraction [14], [15], subcritical water extraction [16], were to produce of phenolic compounds. However, the extraction yield obtaining from the extraction is quite low. The presence of solvents used in some extractions and has been done using organic solvents that can affect when applied to the food industry, pharmaceutical and other sectors. Extraction technology using microwave radiation is likely to produce uniform heating in the process. So, it have to

Yeni Variyana and Mahfud Mahfud are with Department of Chemical Engineering, Institut Teknologi Sepuluh Nopember, Surabaya, 60111, Indonesia. E-mail: mahfud@chem-eng.its.ac.id
TABLE 1.

INDEPENDENT VARIABLES AND LEVELS USED IN BOX-BEHNKEN DESIGN (BBD)

\begin{tabular}{lccc}
\hline \hline Name & Unit & Low level & High level \\
\hline Mass of material & $\mathrm{g}$ & 50 & 150 \\
Microwave power & $\mathrm{W}$ & 300 & 600 \\
Extraction time & $\mathrm{min}$ & 10 & 20 \\
\hline \hline
\end{tabular}

improve the quality and quantity of products from the extraction process. Microwave heating is very effective when used in materials containing water. Because it can absorb energy from these microwaves very well, in a process called dielectric heating (dielectric constant) [17]. Allium cepa has a water content about $80 \%$. The moisture content of it is expected to dissolve the extract component well. The extraction performance of Allium cepa using microwave has the potential to produce higher yields and better extract quality.

Nowadays appears a method without solvent for the extraction process. Of course, this method will make the extraction yield will be more quality and not be contaminated product. This method is called solvent-free microwave extraction (SFME), which is expected to be green technology due to the better process. This method is also effective for the extraction of bioactive and the main compounds from plants. Extraction using SFME method in onion has been done, but still has not found optimum condition to produce the extract [18]. In addition, this method would be combined with gravity technique. Therefore, this research also conducted an optimization to know what variables are influential in order to obtain optimum conditions.

The response surface methodology (RSM) is designed to analyze in terms of statistical and mathematical design [19]. Other than that, it is an important technology for developing new processes, optimizing its performance, and improving the design of process condition. Again, the main purpose of RSM from this study usually to analyze and discuss about the single parameter effect, the interaction of parameters, including the result of the maximum, in range, and minimum for the formation of 
TABLE 2.

BOX-BEHNKEN DESIGN MATRIX AND RESPONSE FOR THE EXTRACTION YIELD FROM ALLIUM CEPA

\begin{tabular}{cccccc}
\hline \hline & Parameter & & \multicolumn{3}{c}{ Response (yield, \%) } \\
\hline \multirow{2}{*}{ Run } & $\begin{array}{c}\text { Mass of raw material } \\
(\mathrm{g})\end{array}$ & $\begin{array}{c}\text { Microwave power } \\
(\mathrm{W})\end{array}$ & $\begin{array}{c}\text { Extraction time } \\
(\mathrm{min})\end{array}$ & Observed & Predicted \\
\hline 1 & 100 & 450 & 15 & 2.49 & 2.53 \\
2 & 150 & 600 & 15 & 2.33 & 2.33 \\
3 & 150 & 450 & 10 & 1.73 & 1.71 \\
4 & 100 & 450 & 15 & 2.59 & 2.53 \\
5 & 100 & 600 & 10 & 1.16 & 1.17 \\
6 & 100 & 300 & 10 & 0.73 & 0.8 \\
7 & 100 & 300 & 20 & 1.89 & 1.88 \\
8 & 50 & 450 & 10 & 0.57 & 0.5 \\
9 & 50 & 450 & 20 & 1.57 & 1.59 \\
10 & 100 & 450 & 15 & 2.46 & 2.53 \\
11 & 50 & 600 & 15 & 0.67 & 0.72 \\
12 & 100 & 450 & 15 & 2.54 & 2.53 \\
13 & 50 & 300 & 15 & 0.95 & 0.94 \\
14 & 150 & 300 & 15 & 1.61 & 1.55 \\
15 & 150 & 450 & 20 & 2.52 & 2.59 \\
16 & 100 & 600 & 20 & 2.15 & 2.07 \\
17 & 100 & 450 & 15 & 2.57 & 2.53 \\
\hline \hline
\end{tabular}

TABLE 3 .

LACK OF FIT TESTS FROM DESIGN EXPERT

\begin{tabular}{rcccccc}
\hline Source & Sum of Squares & Df & Mean Square & F-value & p-value & \\
\hline Linear & 4.21 & 9 & 0.4675 & 169.63 & $<0.0001$ & \\
2FI & 3.94 & 6 & 0.6569 & 238.33 & $<0.0001$ & Suggested \\
Quadratic & $\mathbf{0 . 0 2 9 5}$ & $\mathbf{3}$ & $\mathbf{0 . 0 0 9 8}$ & $\mathbf{3 . 5 6}$ & $\mathbf{0 . 1 2 5 7}$ & Aliased \\
Cubic & 0.0000 & 0 & & & & \\
\hline \hline
\end{tabular}

TABLE 4.

MODEL SUMMARY STATISTICS FOR EXTRACTION YIELD USING RESPONSE SURFACE

\begin{tabular}{cccccc}
\hline \hline Source & $\begin{array}{c}\text { Sequential } \\
\text { p-value }\end{array}$ & $\begin{array}{c}\text { Lack of fit } \\
\text { p-value }\end{array}$ & Adjusted R $^{2}$ & Predicted R $^{\mathbf{2}}$ & \\
\hline Linear & 0.0203 & $<0.0001$ & 0.4062 & 0.2889 & \\
2FI & 0.8771 & $<0.0001$ & 0.2768 & -0.0802 & Suggested \\
Quadratic & $<\mathbf{0 . 0 0 0 1}$ & $\mathbf{0 . 1 2 5 7}$ & $\mathbf{0 . 9 8 9 4}$ & $\mathbf{0 . 9 4 4 1}$ & Aliased \\
Cubic & 0.1257 & & 0.9950 & & \\
\hline
\end{tabular}

region that produce the highest response of the extraction process. Especially, in the industrial sector, a very important problem is determining the conditions that optimize the process to get high yield, low cost, and appropriate concentration.

Thus, the aim of the present work was to evaluate the effects of the extraction parameters of mass of raw material, microwave power and extraction time for the extraction yield from Allium cepa using solvent-free microwave extraction and hydro-diffusion gravity method that is the best of our knowledge, no work has been published before. Further, optimize the extraction conditions using Surface Response Methodology (RSM). In this study would expected to be used as an effective method to produce the higher for the extraction yield.

\section{METHOD}

\section{A. Materials}

Allium cepa was purchased at a local market in Surabaya, East Java, Indonesia. It was peeled and chopped into slices about $\pm 5 \mathrm{~mm}$. A solvent of $\mathrm{n}$-hexane (the boiling point of $69^{\circ} \mathrm{C}$ ) was purchased from Merck (Darmstadt, Germany). It used as the extracting solvent to take of onion oil after the extraction process.

\section{B. Microwave Hydro-diffusion Gravity}

Microwave hydro-diffusion gravity of extraction process did gravity process. The microwave was used for experiment from Electrolux of EMM2308X model with the following specifications: maximum power of $800 \mathrm{~W}$,
$220 \mathrm{~V}$ voltage, $1250 \mathrm{~W}$ power, magnetron frequency of $2450 \mathrm{MHz}(2.45 \mathrm{GHz})$. Reactor as to contain material inside microwave connected to Condensor below it and in the bottom separating funnel as container. For SFME extraction process, $1000 \mathrm{ml}$ sized reactor (round bottom flask) containing mass of raw material at 50;100;150 g of fresh onion was placed in the flask. Microwave power was set at $300 ; 450 ; 600 \mathrm{~W}$ and extraction time in $10 ; 15 ; 20$ min. After extraction process, the extract was separated water and added n-hexane to collect the onion oil. Then, it was evaporated over to remove excess of n-hexane at atmospheric condition. The onion oil was weighed and stored in vial at $3^{\circ} \mathrm{C}$ for further analysis. The extraction yield of onion oil was calculated according to the equation as follows:

$Y(\%)=\frac{\text { Mass of onion oils }}{\text { Mass of fresh onion (1-moisture content(\%)) }} \times 100$ (1)

C. Experimental and statistical analysis of the extraction yield from Allium cepa

Three-factors (see Table 1) in Box-Behnken Design (BBD) [20], [21] was applied to optimize and analyze the extraction conditions in order to obtain a high yield from fresh Allium cepa. The three independent variables set were mass of material $(\mathrm{g})$, microwave power (W) and extraction time ( $\mathrm{min})$. A total of 17 experiments with 6 of center point per block was designed in Table 2 which each of experiments was performed in triplicate and the yield of extract (mg/g dry basis) was taken as the response, Y. 
TABLE 5.

ANALYSIS OF VARIANCE (ANOVA) OF QUADRATIC MODEL TO IDENTIFY SIGNIFICANT FACTORS AFFECTING THE EXTRACTION YIELD

\begin{tabular}{lcccccl}
\hline \hline Sources & Sum of Squares & df & Mean Square & F-value & p-value & \\
\hline Model & 8.7 & 9 & 0.967 & 167.22 & $<0.0001$ & significant \\
A-Mass of raw material & 2.44 & 1 & 2.44 & 421.1 & $<0.0001$ & \\
B-Microwave power & 0.1574 & 1 & 0.1574 & 27.22 & 0.0012 & \\
C-Extraction time & 1.93 & 1 & 1.93 & 334.18 & $<0.0001$ & \\
$\mathrm{AB}$ & 0.2483 & 1 & 0.2483 & 42.95 & 0.0003 & \\
$\mathrm{AC}$ & 0.0106 & 1 & 0.0106 & 1.83 & 0.2183 & \\
$\mathrm{BC}$ & 0.0074 & 1 & 0.0074 & 1.29 & 0.294 & \\
$\mathrm{~A}^{2}$ & 1.1 & 1 & 1.1 & 190.6 & $<0.0001$ & \\
$\mathrm{~B}^{2}$ & 1.67 & 1 & 1.67 & 289 & $<0.0001$ & \\
$\mathrm{C}^{2}$ & 0.7407 & 1 & 0.7407 & 128.09 & $<0.0001$ & \\
Residual & 0.0405 & 7 & 0.0058 & & & \\
Lack of fit & 0.0295 & 3 & 0.0098 & 3.56 & 0.1257 & not significant \\
\hline
\end{tabular}

TABLE 6.

FIT STATISTICS FROM ANOVA FOR THE EXTRACTION PROCESS OF ONION OIL

\begin{tabular}{cc}
\hline \hline Insignificant factors & Extraction yield (Y) \\
\hline Standard deviation & 0.0760 \\
Mean & 1.80 \\
Coefficient of variance \% (CV) & 4.23 \\
$\mathrm{R}^{2}$ & 0.9954 \\
Adjusted $\mathrm{R}^{2}$ & 0.9894 \\
Predicted $\mathrm{R}^{2}$ & 0.9441 \\
Adeq Precision & 35.7729 \\
\hline \hline
\end{tabular}
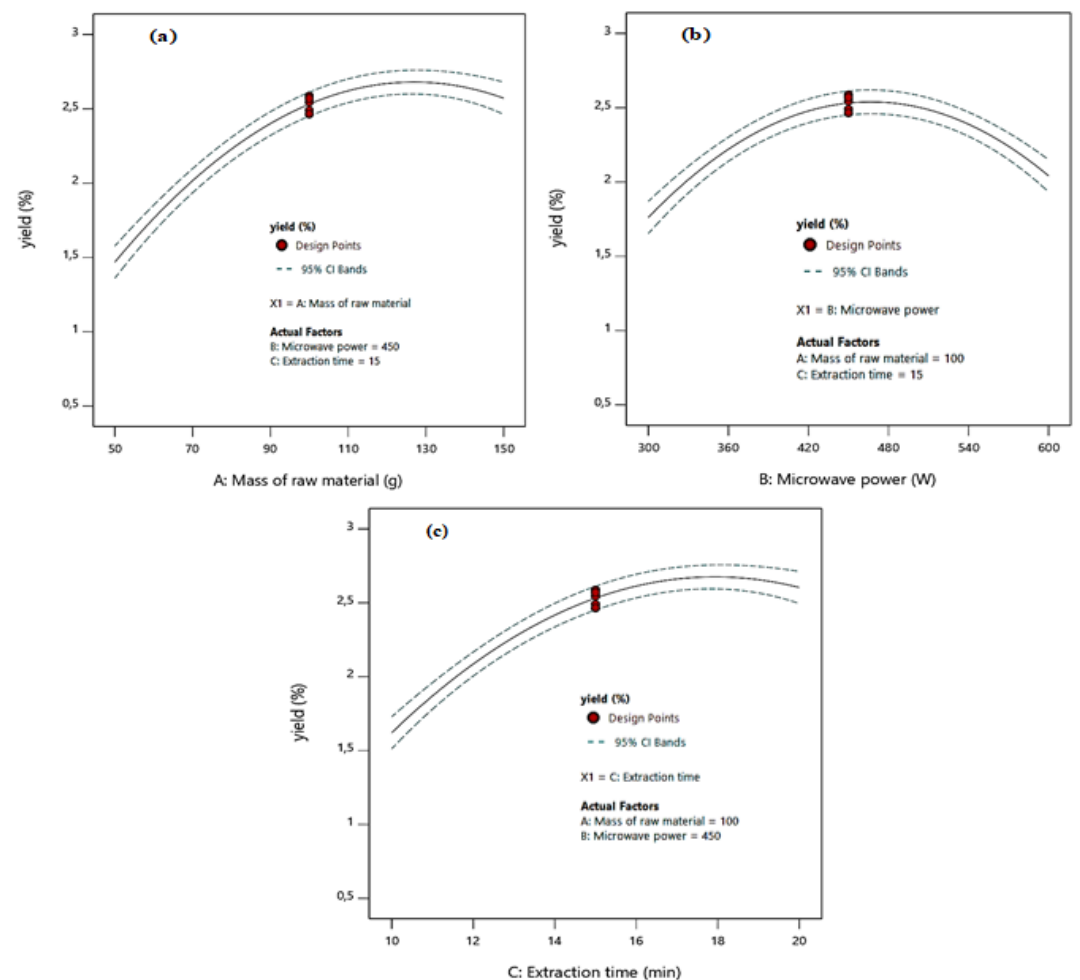

Figure 1. Effect of single parameter are (a) mass of raw material; (b) microwave power; (c) extraction time.

This is the same as the design carried out by Ye (2012) [15].

Regression analysis was performed for the experimental data and was fitted into the second-order model, as follows equation below:

$Y=\beta_{0}+\sum_{i=1}^{3} \beta_{i} X_{i}+\sum_{i=1}^{3} \beta_{i i} X_{i}^{2} \sum_{i=1}^{2} \sum_{j=i+1}^{3} \beta_{i j} X_{i} X_{j}$

where $\beta_{0}, \beta_{i}, \beta_{i i}$ and $\beta_{i j}$ are regression coefficients in the intercept, linear, quadratic, and interaction terms, severally; $\mathrm{Xi}$ and $\mathrm{Xj}$ are the independent variables. The Design-Expert 11 software package (trial version; StateEase Inc., Minneapolis, USA) was used to obtain the coefficients of the quadratic polynomial model. The quality of the fitted model was stated by $\mathrm{p}$-value, $\mathrm{R}^{2}$, coefficient of variation (CV) and its statistical significance was expressed by an F-test and lack of fit.

\section{RESULTS AND DISCUSSION}

\section{A. Single factor effect analysis}

Figure 1a. resulted that effect of mass of raw material, which can increase the yield. The mass is closely related to the volume of solvent used to produce high extracts. However, in this study was used method without solvent so that the solvent position was replaced by an internal solvent in onion. The water contained in the material as solvent to prevent excessive heating and medium for transferring heat. Besides that, the influence of mass on the extraction from Allium cepa is raised so it can produce 

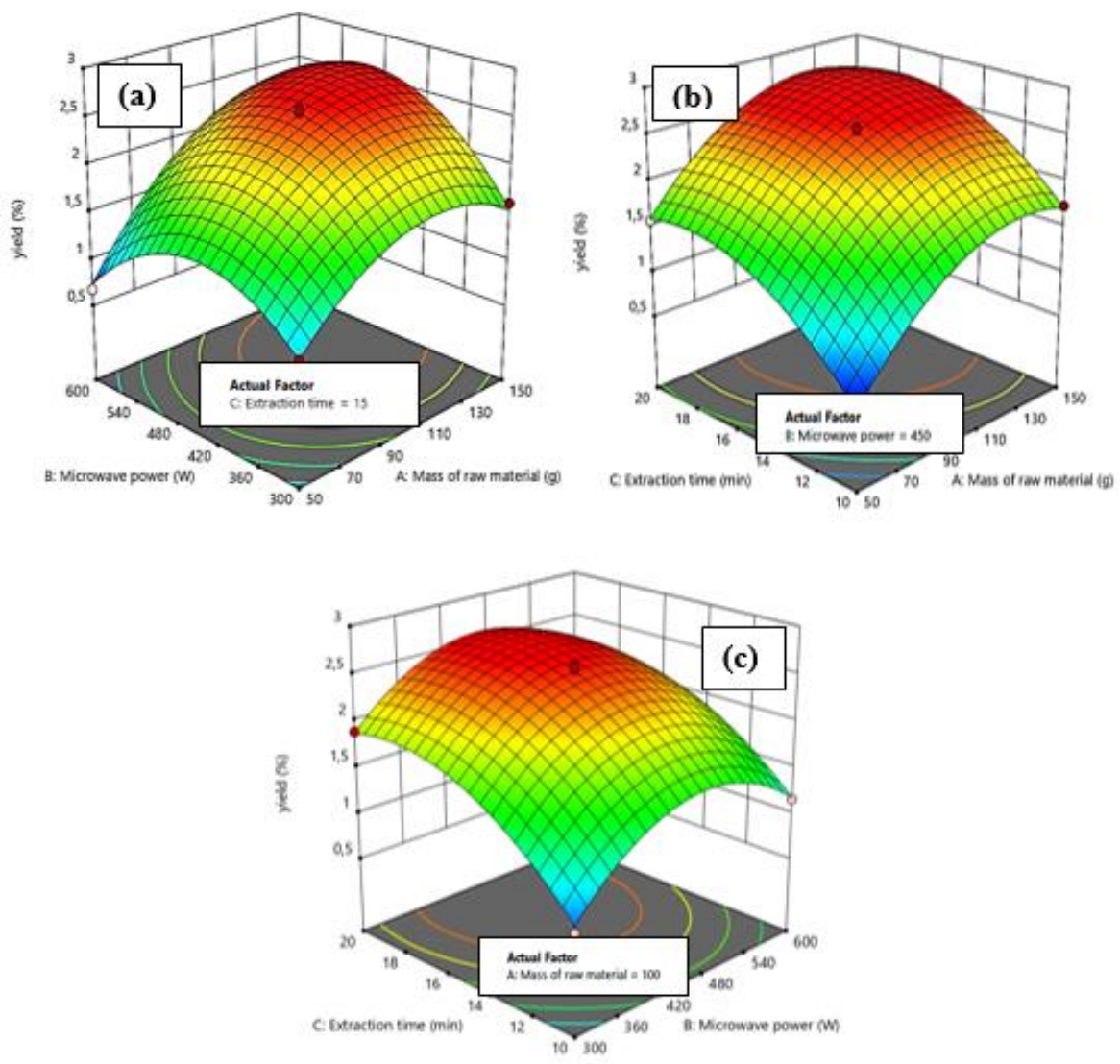

Figure 2. Response surface plots showing the interaction effect of (a) mass of raw material and microwave power at constant extraction time (15 min); (b) mass of raw and extraction time at constant microwave power $(450 \mathrm{~W})$; (c) microwave power and extraction time at constant mass of raw material.

larger yield as well. From the result, when the mass of raw material is $50 \mathrm{~g}$ to $100 \mathrm{~g}$, it will produce greater results. However, mass of $150 \mathrm{~g}$ causes a slight decrease in the extract yield. This might occur because the amount of raw material in $100 \mathrm{~g}$ has higher water content to dissolve the targeted molecules, thus it can increase the highest yield of extraction.

The extraction process from Allium cepa in Figure $1 \mathrm{~b}$. showed that microwave power at 50;100;150 W. Extraction yield increases significantly before the microwave power reaches of $600 \mathrm{~W}$. Based on optimized at $300 \mathrm{~W}$, the yield increases up to $450 \mathrm{~W}$, and then decrease afterwards. The results of this study were similarly reported by Mollaei et al. (2019), there is a decrease in yield when it is at the highest power in the extraction process [22]. Actually, microwave power increased linearly increasing temperatures. The might be caused because microwave induced micro-molecular movements that can easily produce onion oil in two ways. First, magnetic waves heat water in the cell, exerting internal pressure and rupturing oil glands. Second, high temperatures also damage the surface tension and, in turn, the viscosity of water, causing heat transfer faster from the outside into the material [23]. However, for very high temperatures, some substances are sensitive to temperature in oils that it can decompose. The phenomenon will affect the results of extraction, oil quality, and production costs due to increase energy consumption [23]. As similar result was reported by Yang (2011), in the highest level of microwave power, the oil yield from Allium cepa was decreased that might caused by decomposing the materials [24]. So, microwave power at $450 \mathrm{~W}$, is recommended level for the extraction process from Allium cepa.

The extraction process has been set in microwave power at $450 \mathrm{~W}$. Figure 1c. can be seen from the figure that the extraction time has a significant impact on the yield of onion oil. The existence of a significant yield will increase from $10-15 \mathrm{~min}$ after that slightly decreased in the condition of $20 \mathrm{~min}$. Generally, longer extraction time improves the higher yield from the extraction. Possible reason of yield decline after reaching $10 \mathrm{~min}$ are suspected of material decomposition and material sustain degradation when the extraction process occurred. As similar was reported by Pan et al. (2002) that extract will give decreasing yield with the increase of extraction time. In addition, it will easily decompose when exposed to high temperatures for long periods of time [25]. Therefore, the optimal extraction time was chosen at 15 min for MHG technique.

\section{B. Model Fitting for the extraction process of Allium cepa}

Testing for lack of fit is a main result of the response surface methodology, when executed, it can be completely random. The test must always be carried out before interpreting the polynomial that matches the response surface model. If it does not produce insignificant for lack of fit, we will look for the output of other models in response surface more acceptable. The selected model should have an insignificant lack of fit. Based on criteria in Table 3, the value should have about the lack of fit $>0.1$ [26].

Design-Expert tests (see Table 4.) to fit a series of models in response surface to the data are linear (first- 


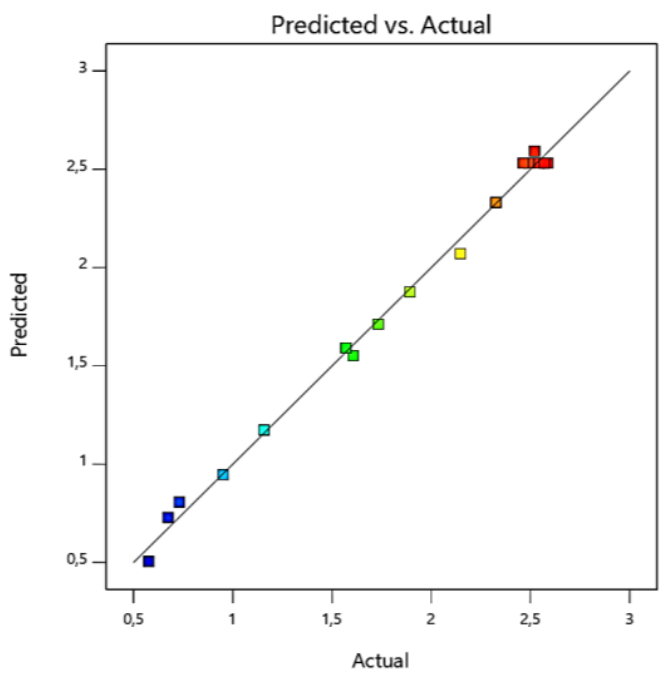

Figure 3. Model graph for comparison between predicted model and experimental data.

order), 2FI (first-order with interaction), quadratic (second-order), and cubic. The significant model is evaluated for each value of p-value, F-test and lack of fit that are in accordance with the correct statistical standards. Model summary showed that sequential pvalue less than 0.05 is only quadratic model. Lack of fit of all models considered that are can be used and valid. Moreover, Adjusted $\mathrm{R}^{2}$ and predicted $\mathrm{R}^{2}$ should approach about 1 . Cubic model has the highest value of adjusted $R^{2}$ but the model cannot use $(p>0.05)$ because of not recommended for second-order model.

The fitting parameter showed that the actual or experimental data can be evaluated to fit the statistical result. The model coefficients are represented by constant terms, linear coefficients for independent variables, interactive term coefficients, coefficients of quadratic terms. Then, the determination coefficient $\left(R^{2}\right)$, the adjusted coefficient of determination $\left(\operatorname{Adj}-R^{2}\right)$ and adequate precision are used to evaluate the adequacy of the model; this model is adequate when the value of $\mathrm{p}$ $<0.05$; lack of fit $\mathrm{p}>0.05$; and $\mathrm{R}^{2}>0.9$ [27]. Then, summary statistics suggest to selecting the quadratic model for this extraction process, which is model selected by Design-Expert.

\section{Analysis of variance (ANOVA)}

From the Table 5. ANOVA with quadratic model is significant. The factors are mass of raw material (A), microwave power (B), and extraction time (C) show important values for all factors with responses. Moreover, the quadratic model could give the interaction of each factor and design for each combination of the factorial experiment used for the process variables.

The interaction between the mass of raw material and microwave power $(\mathrm{AB})$ was insignificant $(\mathrm{p}<0.05)$ which means that the factors was fitted and accepted for the extraction process analysis. Then, the mass of raw material and extraction time (AC) interaction showed insignificant results $(\mathrm{p}>0.05)$. Moreover, the interaction between microwave power and extraction time (BC) results of ANOVA also performed insignificant ( $p>0.05)$. However, generally, the model response of the all interaction of various factors could be used as a match between experimental data and predictive model for extraction process from Allium cepa.

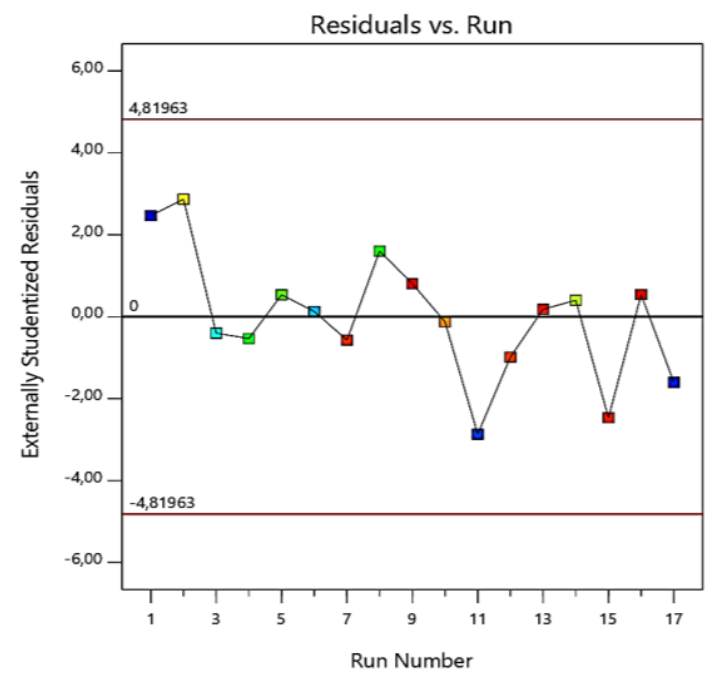

Figure 4. Normal plot of residuals with run.

The analysis of variance in ANOVA (Table 5.) for the quadratic model gives the result of $\mathrm{p}<0.05$; lack of fit from ANOVA is $\mathrm{p}>0.05$ that the model is logic and accurate [23]; the model of F-value of 167.22 implies the model is significant; the results were indicated the goodness of fit from correlation of factors in regression analysis [28]. All factors were influenced for optimizing to produce yield. On the other hand, the model was indicated and significant result which has affected to analyze the optimal conditions. Therefore, these experimental data and predictive model could be applied and accepted for obtaining on the highest of oil yield.

The quadratic model (see Table 6.) resulted $\mathrm{R}^{2}$ in 0.9954 $\left(\mathrm{R}^{2}\right.$ value is closer to 1 ), showing good correlation. The predicted $\mathrm{R}^{2}$ of 0.9441 is in reasonable agreement with the adjusted $R^{2}$ in 0.9894 . It is adeq precision $>4$ indicates an adequate signal and model can be used to navigate the design. The standard deviation of the model is 0.0163 . A small value of the standard deviation shows a good correlation that has a close value between the experimental data and predicted model for the model response [29]. Moreover, the coefficient of variation (CV) of less than $5 \%$, which means the model can be used for operating conditions with a suitable fitted response surface and it has quality fit [30], [31]. The results of the second-order equation for the model are as follows:

$\mathrm{Y}(\%)=2.5313+0.5517 \mathrm{~A}+0.1402 \mathrm{~B}+0.4914 \mathrm{C}+0.2491 \mathrm{AB}+$ $0.0514 \mathrm{AC}-0.0431 \mathrm{BC}-0.5116 \mathrm{~A}^{2}-0.6300 \mathrm{~B}^{2}-0.4194 \mathrm{C}^{2}$

\section{Analyzes of Contour Plots}

The constant condition at extraction time of $15 \mathrm{~min}$ in Figure 2a. The interaction of mass of raw material and microwave power (AC) contributes to the extraction yield. The interaction investigates that both of them could obtain maximum response. The contour showed that the yield of onion oil is linearly results for obtaining the yield. Otherwise, the lower of mass and microwave power would be resulted the minimum yield. Therefore, the extraction process happened from research to obtain the highest onion oil for extraction yield at $450 \mathrm{~W}$. However, if the power is higher and lower than this one will cause a decrease in the yield. While the response of mass of raw material (Allium cepa) to obtain the best yield of $100 \mathrm{~g}$. It also had a proportional value for contributing the onion oil. Besides that, from contour plot, the extraction process 
might be mass of raw material, more sensitive than microwave power.

Mass from Allium cepa and microwave power would decrease to obtain the yield if it crosses the optimum limit of the release from it. Both of two factors can affect the extraction yield. Known, a study states that solvent-free microwave extraction is method without adding any solvent causing the combination process of heat and mass transfer in the microwave. The existence of microwave heating would be caused increasing the temperature in the extraction process quickly, where the evaporation process is increasingly limited [18]. This is probably allows damage and decrease for extraction yield because there is a disruption in the condensation of the extraction process. Moreover, according to Wang (2008) reported that the extraction process would be faster if there was increasing temperature which it is linearly increasing with microwave power and the possibility of changes in composition of compounds [32].

Figure $2 \mathrm{~b}$. given that extraction condition produced in constant microwave power at $450 \mathrm{~W}$. Then, the effects of mass and extraction time (AC) gives response around maximum conditions. The interaction, both of the two affect for contributing to produce on the yield. In this contour response, the optimum conditions are very near $100 \mathrm{~g}$ and $15 \mathrm{~min}$ from experiment. Thus, interactions between the mass and extraction time could be evaluated. From surface plots that the result is as sensitive as between extraction time and mass of raw material.

Generally, the greater the extraction time and mass would be obtained the higher on the yield. Again, this result is similar as before which states that it has passed the equilibrium condition so it might be decreased to the extraction result. As research was conducted by Wang Y (2008) which states that longer of extraction time, the higher yield of extraction. But, the yield is decreasing with the length of time when it has passed its optimum time [32].

Figure 2c. show the response and contour plots for interaction for microwave power and extraction time (BC). Maximum condition determined in mass of Allium cepa of $100 \mathrm{~g}$. In general, it could be seen that the influence of microwave power and extraction time contributes to the yield. The position for the optimum state is around $450 \mathrm{~W}$ in the extraction time $15 \mathrm{~min}$. The optimization results show that the optimum point is in that range of it. Conversely, the minimum conditions at $300 \mathrm{~W}$ and the extraction time would be produced low to the yield. In general, the effect of microwave power and extraction time will produce high extract. As similar with study conducted by Huma (2009) that extraction efficiency depends on the power level and the extraction time determined, which the result of both effects is to produce the same phenomenon [33]. It can also be seen that extraction time is more dominant on the effect of yield than microwave power.

\section{E. Comparison between predicted model and experimental data}

Experimental data and the predicted model from Figure 3. has intersect that be considered as good. This confirms that using a quadratic model can be used as an optimization method to determine the optimal conditions in the extraction process from Allium cepa. The results of the graph show clearly the point between experimental data and predicted are fitted and almost precision. Besides, that corresponds to predict and actual values are scattered in linear lines at close range, indicating that actual results are accurately predicted.

In addition, Fig. 4 showing a plot of the normal probability of residual students, each group of additional terms was assessed sequentially using the partial that Ftest discussed before. The experimental model is considered quite appropriate because the residual value calculated follows a random pattern. Points are represented as squares according to the actual running experiments. Blue, cyan, green, and red colors indicate an increase in the order of actual results according to what is presented. In addition, it shows that data points is suitable to modeling. The correspond to predictive model and actual data are spread over a 45-degree line with at close range, indicating that actual results are accurately predicted from factor values [23].

\section{$F$. Verification and validation for optimizing conditions of the extraction process}

The response for each noise factor after this optimization is done using a desirability function technique. According to Raissi and Farsani (2009), the desirability function approach the ideal interval and reach the goal or target value when the desirability value is 1 [34]. In the study from Allium cepa was to evaluate the effect of parameters using solvent-free microwave extraction method and microwave hydro-diffusion gravity technique. Based on the quadratic model, the optimum conditions calculated for optimization of onion oil when mass of raw material (99.738 g), microwave power $(465.067 \mathrm{~W})$ and extraction time $(17.817 \mathrm{~min})$. It was chosen by none the std error of yield. While the results of the experimental data obtain the highest yield conditions at $100 \mathrm{~g}, 450 \mathrm{~W}$ and $15 \mathrm{~min}$ is $2.5875 \%$, which is very close to the predicted value of $2.677 \%$. This indicates that the model is accurate to predict the expected optimal. Besides, the error rates between the experimental data and predicted model which are less than $5 \%$.

Therefore, the extraction process from Allium cepa for any parameters of mass of raw material, microwave power and extraction time could be accurately predicted by the regression quadratic model designed by response surface methodology.

\section{CONCLUSION}

The extraction process of onion oil using solvent-free microwave extraction (SFME) and microwave hydrodiffusion gravity (MHG) were already done research. Optimization studies from extraction confirm that independent factors are mass of raw material, microwave power, extraction time, and some of the interactions. All of factors significant influence the extraction process to produce the onion oil. The quadratic model was evaluated to get a good fitting between experimental data and predicted model. Experiment resulted that the condition to obtain the highest yield is $100 \mathrm{~g}, 450 \mathrm{~W}$ and $15 \mathrm{~min}$. The optimum condition predicted in $99.738 \mathrm{~g}, 465.067 \mathrm{~W}$, and $17.817 \mathrm{~min}$ to produce the highest yield, which was suggested by response surface methodology (RSM). Therefore, from this study provides an improved new technique of extraction and optimization of factor 
parameters involved for the extraction process of onion oil, which have a better potential for an industrial scale or other purposes.

\section{REFERENCES}

[1] G. Griffiths, L. Trueman, T. Crowther, B. Thomas, and B. Smith, "Onions - A global benefit to health," Phyther. Res., vol. 16, no. 7, pp. 603-615, 2002.

[2] R. B. Maude, "Onion diseases," Epidemiol. Plant Dis., pp. 404-422, 2013

[3] M. Y. Shon, S. Do Choi, G. G. Kahng, S. H. Nam, and N. J. Sung, "Antimutagenic, antioxidant and free radical scavenging activity of ethyl acetate extracts from white, yellow and red onions," Food Chem. Toxicol., vol. 42, no. 4, pp. 659-666, 2004.

[4] B. N. Singh et al., "Polyphenolics from various extracts/fractions of red onion (Allium cepa) peel with potent antioxidant and antimutagenic activities," Food Chem. Toxicol., vol. 47, no. 6, pp. 1161-1167, 2009.

[5] N. Benkeblia, "Antimicrobial activity of essential oil extracts of various onions ( Allium cepa ) and garlic ( Allium sativum )," vol. 37, pp. 263-268, 2004.

[6] C. Ye, D. Dai, and W. Hu, "Antimicrobial and antioxidant activities of the essential oil from onion (Allium cepa L .)," Food Control, vol. 30, no. 1, pp. 48-53, 2013.

[7] M. P. Induja and R. V Geetha, "Antimicrobial activity of Allium cepa against bacteria causing enteric infection," Drug Invent. Today, vol. 10, no. 12, pp. 2489-2492, 2018

[8] K. A. Lee et al., "Antioxidant activities of onion (Allium cepa L.) peel extracts produced by ethanol, hot water, and subcritical water extraction," Food Sci. Biotechnol., vol. 23, no. 2, pp. 615-621, 2014

[9] M. Fragis, A. I. Murayyan, and S. Neethirajan, "Cytotoxic activity and anti-cancer potential of Ontario grown onion extracts against breast cancer cell lines," Funct. Foods Heal. Dis., vol. 8, no. 3, pp. 159-174, 2018.

[10] H. Wu and B. Xu, "Inhibitory effects of onion against $\alpha$ glucosidase activity and its correlation with phenolic antioxidants," Int. J. Food Prop., vol. 17, no. 3, pp. 599-609, 2014.

[11] F. J. Vazquez-Armenta, M. R. Cruz-Valenzuela, and J. F. Ayala-Zavala, Onion (Allium cepa) essential oils. Elsevier Inc., 2015.

[12] M. Søltoft, J. H. Christensen, J. Nielsen, and P. Knuthsen, "Pressurised liquid extraction of flavonoids in onions. Method development and validation," Talanta, vol. 80, no. 1, pp. 269278, 2009.

[13] J. Santas, R. Carbó, M. H. Gordon, and M. P. Almajano, "Comparison of the antioxidant activity of two Spanish onion varieties," Food Chem., vol. 107, no. 3, pp. 1210-1216, 2008.

[14] K. G. Martino and D. Guyer, "Supercritical fluid extraction of quercetin from onion skins," J. Food Process Eng., vol. 27, no. 1 , pp. 17-28, 2004.

[15] C.-L. Ye and Y.-F. Lai, "Supercritical CO 2 Extraction Optimization of Onion Oil Using Response Surface Methodology," Chem. Eng. Technol., vol. 35, no. 4, pp. 646652, 2012.

[16] M. J. Ko, C. I. Cheigh, S. W. Cho, and M. S. Chung, "Subcritical water extraction of flavonol quercetin from onion skin," J. Food Eng., vol. 102, no. 4, pp. 327-333, 2011.

[17] U. Kaatze and V. Uhlendorf, "The dielectric properties of water at microwave frequencies," Zeitschrift fur Phys. Chemie, vol. 126, no. 2, pp. 151-165, 1981.

[18] H. Zill-e-huma, Microwave Hydro-diffusion and gravity: a novel technique for antioxidants extraction To cite this version: HAL Id : tel-00547428 Zill-e-Huma. 2010.

[19] M. N. Braimah, A. N. Anozie, and O. J. Odejobi, "Utilization of Response Surface Methodology ( RSM ) in the Optimization of Crude Oil Refinery," J. Multidiscip. Eng. Sci. Technol., vol. 3, no. 3, pp. 4361-4369, 2016.

[20] J. Yu, D. V Dandekar, R. T. Toledo, R. K. Singh, and B. S. Patil, "Food Chemistry Supercritical fluid extraction of limonoids and naringin from grapefruit ( Citrus paradisi Macf .) seeds," Food Chem., vol. 105, pp. 1026-1031, 2007.

[21] J. Wang, B. Sun, Y. Cao, Y. Tian, and X. Li, "Food Chemistry Optimisation of ultrasound-assisted extraction of phenolic compounds from wheat bran," Food Chem., vol. 106, pp. 804$810,2008$.

[22] S. Mollaei, F. Sedighi, B. Habibi, S. Hazrati, and P. Asgharian, "Extraction of essential oils of Ferulago angulata with microwave-assisted hydrodistillation," Ind. Crops Prod., vol. 137, pp. 43-51, 2019.

[23] T. Tran et al., "Optimization of Microwave-Assisted Extraction of Essential Oil from Vietnamese Basil (Ocimum basilicum L.) Using Response Surface Methodology," Processes, vol. 6, no. 11, p. 206, 2018.

[24] L. M. Yang, L. L. Han, and Z. Yang, "Microwave-Assisted Extraction of Garlic Essential Oil from Garlic," Appl. Mech. Mater., vol. 117-119, pp. 1022-1026, 2012.

[25] X. Pan, G. Niu, and H. Liu, "Comparison of microwaveassisted extraction and conventional extraction techniques for the extraction of tanshinones from Salvia miltiorrhiza bunge," Biochem. Eng. J., vol. 12, no. 1, pp. 71-77, 2002.

[26] R. H. Myers, D. C. Montgomery, and C. M. Anderson, Response Response Methodology, 3rd ed. Canada: John Wiley \& Sons, Inc., Hoboken, New Jersey Published, 2009.

[27] A. Y. Aydar and O. Köseoğlu, "Effect of ultrasound on olive oil extraction and optimization of ultrasound-assisted extraction of extra virgin olive oil by response surface methodology (RSM)," Grasas y Aceites, vol. 68, no. 2, pp. 111, 2017.

[28] H. Cui et al., "Essential oils from Carex meyeriana Kunth: Optimization of hydrodistillation extraction by response surface methodology and evaluation of its antioxidant and antimicrobial activities," Ind. Crops Prod., vol. 124, no. August, pp. 669-676, 2018.

[29] S. K. Behera, H. Meena, S. Chakraborty, and B. C. Meikap, "Application of response surface methodology (RSM) for optimization of leaching parameters for ash reduction from low-grade coal," Int. J. Min. Sci. Technol., vol. 28, no. 4, pp. 621-629, 2018.

[30] Z. Y. Zhao, Q. Zhang, Y. F. Li, L. L. Dong, and S. L. Liu, "Optimization of ultrasound extraction of Alisma orientalis polysaccharides by response surface methodology and their antioxidant activities," Carbohydr. Polym., vol. 119, pp. 101109, 2015

[31] P. K. J. P. D. Wanasundara and F. Shahidi, "Optimization of Hexametaphosphate-Assisted Extraction of Flaxseed Proteins Using Response Surface Methodology," J. Food Sci., vol. 61, no. 3, pp. 604-607, 1996.

[32] Y. Wang et al., "Analysis of ginsenosides in Panax ginseng in high pressure microwave-assisted extraction," Food Chem. vol. 110 , no. 1, pp. 161-167, 2008.

[33] Z. Huma, A. M. Vian, J. F. Maingonnat, and F. Chemat, "Clean recovery of antioxidant flavonoids from onions: Optimising solvent free microwave extraction method," $J$. Chromatogr. A, vol. 1216, no. 45, pp. 7700-7707, 2009.

[34] S. Raissi and R.-E. Farsani, "Statistical Process Optimization Through Multi-Response Surface Methodology," Int. J. Math. Comput. Sci., vol. 3, no. 3, pp. 197-201, 2009. 